\title{
Medical care usage and self-rated mental health
} James E Rohrer*

\author{
Address: Division of Health Services Research, Texas Tech University Health Sciences Center, Amarillo TX, USA \\ Email: James E Rohrer* - james.rohrer@ttuhsc.edu \\ * Corresponding author
}

Published: 23 February 2004

BMC Public Health 2004, 4:3
Received: 08 December 2003

Accepted: 23 February 2004

This article is available from: http://www.biomedcentral.com/l47I-2458/4/3

(C) 2004 Rohrer; licensee BioMed Central Ltd. This is an Open Access article: verbatim copying and redistribution of this article are permitted in all media for any purpose, provided this notice is preserved along with the article's original URL.

\begin{abstract}
Background: Population studies frequently employ a single item dependent variable for overall health. Self-rated mental health has been the focus of attention less often. The purpose of this project was to investigate the relationship between use of medical care and poor mental health in an elderly population.

Methods: This study involved a cross-sectional telephone survey of persons over 65 years of age in West Texas, a sparsely-populated 108-county region. Independent variables included number of medical visits, race/ethnicity, age, gender and ability to pay for care. Mental health was measured by asking subjects how often they felt downhearted or blue.

Results: Multiple logistic regression analysis revealed that more medical visits were made by persons who were downhearted or blue. Females, persons who had difficulty paying for care, Hispanic respondents, and older persons were more likely to report poor mental health.

Conclusions: Elderly persons in this region who use more medical care are at greater risk of being in poor mental health. Public health agencies that are planning population-based approaches to improving mental health should consider targeting persons who are high users of medical care as well as those of limited means, women, persons of Hispanic ethnicity, and people who are of greater age.
\end{abstract}

\section{Background}

Self-rated health may be more relevant to the goals of community health programs than mortality and morbidity rates. Self-rated health reflects the degree to which people are satisfied with their health and whether they can perform their usual activities, which is more important to most people than whether they are labeled with a particular diagnosis.

The validity of self-rated overall health has been firmly established and frequently studied [1-8]. Self-rated men- tal health is important in its own right. However, the epidemiology of self-rated mental health has not been explored as extensively as overall self-rated health. The international public health community has placed increasing emphasis on mental health. Therefore, epidemiological studies such as the one reported here are of increasing relevance and importance.

Modern societies are stressful, partly due to income inequalities, and the resulting damage to population health is consistent with the theories that drive the field of social 
epidemiology [8]. The failure to recognize and address mental health problems in the population is unfortunate for those persons who suffer from such problems. In addition, demands on the medical care system may be greater than necessary as persons seek care from a system that may not be as prepared to recognize and address mental health problems as it should be. The result might be ineffectiveness and inefficiency in a service delivery system that fails to adequately address poor mental health.

Epidemiological studies of mental health problems pose special measurement problems, because of the need to cost-effectively collect a broad set of measures that are brief yet valid. Measures of physical and mental health used in epidemiological studies have evolved in recent years. Long instruments are regarded as important for studies of patients in clinical settings, but impractical for community surveys. A single item has become the norm for measuring overall health in population studies. Measurement of mental health in population studies also has evolved from complex diagnostic instruments toward shorter scales. For example, a study of older people in Spain used a single item to measure health but 20 items to measure depression [9]. A recent study of medical inpatients used an eight-item symptom checklist to detect anxiety and depression and a seven-item index to mean hypochondriasis [10]. In contrast, the American Journal of Public Health published the results of a national survey that used a single item to measure mental health. The single item was dichotomized (positive versus negative mental health) [11]. The Behavioral Risk Factor Surveillance Survey (BRFSS), which is required of every US state by the Centers of Disease Control, uses a single-item to measure mental health (i.e., the number of recent days when mental health was poor). Single-item measures of mental health are valid because, rather than seeking to assign a clinical diagnosis such as depression, they simply reflect the respondent's perceptions of his or her own mental health. Perceived or self-rated mental health is inherently valid because the respondent is the best judge of his or her own perceptions.

The purpose of the study reported here was to test the hypothesis that persons who make more medical visits have worse self-rated mental health. This hypothesis is based on the theory that the medical care system is suboptimal in its ability to recognize and treat mental health problems. Failure to address the true causes of the person's symptoms could lead to more use of medical care. Therefore, high-use of medical care might be a risk factor for poor mental health in population surveys.

\section{Methods}

The third wave of the Texas Tech 5000 survey $(\mathrm{N}=5,006)$ was used for this analysis. The Texas Tech 5000 was a ran- dom digit dialing telephone survey that involved interviews of persons over age 65 who resided in the 108 counties comprising West Texas. This study was approved by the Institutional Review Board of the Texas Tech University Health Sciences Center. Persons called were screened for cognitive impairment before granting consent to participate in the survey. Seventy-nine percent of eligible persons agreed to the baseline interview, resulting in 5006 enrollees. Telesurveys Research Associates of Houston, Texas collected the data under the auspices of a contract that specified random sampling, multiple callbacks, bi-lingual interviewers, testing for cognitive impairment, and obtaining informed consent. Additional rounds were conducted over the next three years. By the end of the project, 3155 subjects were still participating.

\section{Dependent Variable}

In a study of self-rated health in Vancouver, Dunn measured mental health by asking respondents: "How much of the time in the past two weeks have you felt downhearted and blue?"[4]. This item was used in the Rand Mental Health Inventory with the following possible responses: all of the time, most of the time, a good bit of the time, some of the time, a little of the time, none of the time [5]. The item is reported to have good predictive validity $[6,7]$.

In this study, the following question was used: "During the past four weeks, have you felt downhearted and blue....1) all the time (1.1 percent), 2) most of the time (2.7 percent), 3 ) a good bit of the time (3.5 percent), 4) some of the time (18.1 percent), 5) a little of the time (26.1 percent), or 6 ) none of the time" (48.5 percent). The responses were dichotomized into poor mental health or good mental health. The poor mental health category included respondents who had felt blue "all," "most", or "a good bit" of the time. Good mental health included those who felt blue "some", "a little", or "none" of the time. Categorized in this way, only 7.3 percent of the sample was in the poor mental health category. This variable was dichotomized in order preserve consistency with the approach generally used to analyze self-rated overall health. The split was made between 'a good bit of the time' and 'some of the time' because of the logical difference in the perceived severity of mental health problems that is reflected in these different responses.

\section{Independent Variables}

The number of medical visits in the past year was divided into 5 dummy variables: no visits, 1 visit, 2 visits, 3-4 visits, 5 or more visits with those having no visits as the referent category. The relationship between visits and poor mental health was adjusted for the effects of other independent variables. These are described below. 
Table I: Descriptive Statistics

\begin{tabular}{|c|c|c|c|}
\hline & Percent Blue & Percent Not Blue & Total Cases \\
\hline \multicolumn{4}{|l|}{ Ethnicity/Race } \\
\hline Hispanic & 17.3 & 82.7 & 346 \\
\hline $\mathrm{NH}$ black & 6.8 & 93.2 & 73 \\
\hline $\mathrm{NH}$ white & 5.9 & 94.1 & 2664 \\
\hline Other & 11.5 & 88.5 & 61 \\
\hline \multicolumn{4}{|l|}{ Age } \\
\hline $65-69$ & 6.2 & 93.8 & 737 \\
\hline $70-74$ & 6.6 & 93.4 & 967 \\
\hline $75-79$ & 7.5 & 92.5 & 682 \\
\hline 80 and over & 9.1 & 90.9 & 758 \\
\hline \multicolumn{4}{|l|}{ Gender } \\
\hline Female & 8.7 & 92.3 & 2230 \\
\hline Male & 3.8 & 96.2 & 914 \\
\hline \multicolumn{4}{|c|}{ Avoided Medical Care Due to Cost } \\
\hline Yes & 16.4 & 83.6 & 324 \\
\hline No & 6.3 & 93.7 & 2820 \\
\hline \multicolumn{4}{|l|}{ Medical Visits } \\
\hline None & 7.8 & 92.2 & 258 \\
\hline One & 5.2 & 94.8 & 464 \\
\hline Two to five & 6.4 & 93.6 & 1479 \\
\hline Six to ten & 6.4 & 93.6 & 512 \\
\hline More than ten & 14.3 & 85.7 & 329 \\
\hline
\end{tabular}

Gender was included as an independent variable, with females being the reference category. Race/ethnicity was indicated as either white non-Hispanic, Hispanic, black, or other race. Age was classified as 65-69, 70-74, 75-79, or 80 and over. In order to control for differences in wealth, respondents were asked if they or anyone in their families had avoided using medical care due to its cost in the last year (yes versus no).

A multivariate logistic regression was run to determine if the number of medical visits had an independent relationship with poor self-rated mental health. EpiInfo 2003 was used to perform the analysis.

\section{Results}

Descriptive statistics are shown in Table 1 . The majority of respondents were non-Hispanic White. Of that group, only 5.9 percent reported poor mental health. In contrast, 17.3 percent of Hispanic respondents had felt blue.

The percentage with poor mental health increased with age. Only 6.2 percent of persons between the ages of 65 and 69 had poor self-rated mental health. The percentages increased with each age bracket, reaching a high of 9.1 percent for persons 80 and over.

Gender also was related to poor mental health, with 8.7 percent of women having been blue. In contrast, only 3.8 percent of males had been blue.
People who reported that they had avoided using medical care due to cost were much more likely to have poor mental health than those who had not avoided care (16.4 percent vs. 6.3 percent).

As the number of medical visits increased so did the percentage reporting feeling blue or downhearted. Almost eleven percent of respondents reported more than ten visits in the previous year. Over 14 percent of this group also reported poor mental health-nearly double the percentage found in any of the other categories.

The results of the multiple logistic regression analysis confirmed the apparent relationships seen in the descriptive statistics. As seen in Table 2, the adjusted odds of poor self-rated mental health are significantly lower for people who made no medical visits in comparison to those who made more than ten $(\mathrm{OR}=.49, \mathrm{p}<.0160)$. One visit, two to five visits, and six to ten visits also had lower odds of poor mental health in comparison to ten or more visits (ORs were .37, .44, and .49, respectively, with p-values all less than .01).

All of the control variables were demonstrated to be significantly related to poor self-rated mental health as well. Persons 80 years of age and over had an odds ratio of 2.0 ( $p=.0013$ ) in comparison to those aged 65-69. In comparison to Hispanic respondents, non-Hispanic black and non-Hispanic White respondents were less likely to report 
Table 2: Multivariate Logistic Regression Analysis of Blueness (Final-2*Log-Likelihood: 1442.36, N = 3042)

\begin{tabular}{|c|c|c|c|}
\hline Term & Odds Ratio & $95 \%$ C.I. & P-Value \\
\hline \multicolumn{4}{|l|}{ MD Visits } \\
\hline None & 0.4936 & $0.2779,0.8768$ & 0.0160 \\
\hline One & 0.3667 & $0.2157,0.6234$ & 0.0002 \\
\hline Two to five & 0.4402 & $0.2987,0.6487$ & 0.0000 \\
\hline Six to ten & 0.4894 & $0.3017,0.7939$ & 0.0038 \\
\hline More than ten & 1.0 & & \\
\hline \multicolumn{4}{|l|}{ Age } \\
\hline $65-69$ & 1.0 & & \\
\hline $70-74$ & 1.1912 & $0.7828,1.8126$ & $0.4|4|$ \\
\hline $75-79$ & 1.4475 & $0.9287,2.256 \mathrm{I}$ & 0.1024 \\
\hline 80 AND OVER & 1.9954 & $1.3089,3.0420$ & 0.0013 \\
\hline \multicolumn{4}{|l|}{ Ethnicity/Race } \\
\hline Hispanic & 1.0 & & \\
\hline $\mathrm{NH}$ black & 0.2822 & $0.1067,0.7463$ & 0.0108 \\
\hline $\mathrm{NH}$ white & 0.2553 & $0.1800,0.3622$ & 0.0000 \\
\hline Other & 0.4769 & $0.1988,1.1440$ & 0.0972 \\
\hline \multicolumn{4}{|l|}{ Gender } \\
\hline Female & 1.0 & & \\
\hline Male & 0.4538 & $0.3093,0.6658$ & 0.0001 \\
\hline \multicolumn{4}{|c|}{ Avoided Medical Care Due to cost } \\
\hline Yes & 2.3956 & $1.6672,3.4423$ & 0.0000 \\
\hline No & 1.0 & & \\
\hline
\end{tabular}

poor mental health (ORs were .28 and .26 with p-values .01 and .00). Men were less likely to report poor mental health as well $(\mathrm{OR}=.45, \mathrm{p}=.0001)$. Persons who had avoided using medical care due to cost were more likely to report poor mental health $(\mathrm{OR}=2.40, \mathrm{p}<.0000)$.

\section{Discussion}

While no causal inferences can be made from a cross-sectional study such as this one, the sample size is large and the hypothesis is strongly supported. Furthermore, the study stands at the intersection between public health and health services research. This is an important feature of the research, since the medical care system interacts with population health in a variety of ways. Unfortunately, the field of health services research at times has drifted away from public health. Measures of medical care usage would, ideally, be incorporated into more public health studies in the future.

The medical care system has been chastised for its insensitivity to underlying mental health problems among patients who present with physical symptoms [12]. The problem is regarded as being of sufficient magnitude that medical costs are thought to be higher because of failure to treat mental health problems. The logical conclusion is that treatment of mental health problems would lead to a reduction or 'offset' in the cost of medical care [13]. However, policy analysts dispute the existence of an offset effect, calling it a myth [14].
Regardless of whether medical costs would actually decline if mental health problems were to be adequately addressed, few could argue that high quality primary care would recognize and treat these issues. Nevertheless, efforts directed at improving the quality of mental health services delivered in primary care settings have had mixed results [15]. Therefore, it is not surprising that this study reveals poor self-rated mental health to be associated with higher utilization of medical care.

Several previous reports have demonstrated a relationship between poor mental health and the number of medical visits made [16-19]. In each of these studies, the number of medical visits served as the dependent variable. In all of these studies, persons with poor mental health were shown to be high users of medical visits. For example, the number of days in poor mental health was related to the number of visits in a farming community [16] and the number of days depressed was related to visits in another rural population survey [17].

Studies such as these assume that mental health problems lead to medical visits, which is no doubt a correct assumption. However, public health researchers have not previously used this relationship to identify high-use of medical care as a marker for poor mental health in population studies. The study reported here is the first to do so. 


\section{Conclusions}

The results reported here are contingent on the validity of a single-item measure of self-rated mental health, which may not be accepted by clinicians who focus their energies on diagnoses. However, since single-item measures of physical and overall health are commonly used in epidemiology, a similar approach to mental health should be acceptable in public health.

The results of this study demonstrated that persons who had more medical visits were at risk for feeling downhearted or blue among the elderly in this southwestern region of the United States. These relationships persisted after adjusting for gender, poverty, age, and ethnicity. The fact that persons with poor self rated mental health made more visits to their doctors suggests that primary care providers might be failing to adequately address poor mental health in this group of patients.

Finally, we note the need for more research into the causes of poor mental health in the elderly as well as interventional studies to test new population-level approaches that public agencies may employ to reduce the prevalence of self-rated mental health problems among elderly persons.

\section{Competing interests}

None declared.

\section{Author's contributions}

JER planned the study, directed the data analysis and wrote the paper.

\section{Acknowledgement}

This manuscript was supported, in part, by a grant, No. 90AM2378, from the Administration on Aging, Department of Health and Human Services. Grantees undertaking projects under government sponsorship are encouraged to express freely their findings and conclusions. Points of view or opinions do not, therefore, necessarily represent official Administration on Aging Policy. Ty Borders, Tom Xu and Ahmed Arif worked on the larger survey project, contributing indirectly to this work. In addition, I would like to acknowledge research assistance provided by Pamela Fritz.

\section{References}

I. Burstrom B, Fredlund P: Self rated health: Is it as good a predictor of subsequent mortality among adults in lower as well as in higher social classes? J Epidemiol Community Health 200I, I I:836-40.

2. Finch BK, Hummer RA, ReindI M, Vega WA: Validity of self-rated health among Latino(a)s. Am J Epidemiol 2002, I55:755-9.

3. Heidrich J, Liese AD, Lowel H, Keil U: Self-rated health and its relation to all-cause and cardiovascular mortality in southern Germany. Results from the MONICA Augsburg cohort study 1984-1995. Ann Epidemiol 2002, 5:338-45.

4. Dunn JR: Housing and inequalities in health: a study of socioeconomic dimensions of housing and self reported health from a survey of Vancouver residents. J Epidemiol Community Health 2002, 56:67|-68I.

5. Brook RH, Ware Jr JE, Davies-Avery A, Stewart AL, Donald CA, Rogers WH, Williams KN, Johnston SA: Overview of adult health measures fielded in Rand's health insurance study. Med Care 1979, I7(7 Suppl): I-I3I.

6. Berwick DM, Murphy JM, Goldman PA, Ware Jr JE, Barsky AJ, Weinstein MC: Performance of a five-item mental health screening test. Med Care 199I, 2:169-76.

7. Weinstein MC, Berwick DM, Goldman PA, Murphy JM, Barsky AJ: A comparison of three psychiatric screening tests using receiver operating characteristic (ROC) analysis. Med Care 1989, 27(6):593-607.

8. Pickhart H, Bobak M, Rose R, Marmot M: Household item ownership and self-rated health: material and psychosocial explanations. BMC Public Health 2003, 3:38.

9. Zunzunegui $M$, Beland $F$, Otero A: Support from children, living arrangements, self-rated health and depressive symptoms of older people in Spain. International Journal of Epidemiology 200 I, 30: 1090-1099.

10. Hansen M, Fink P, Frydenberg M, Oxhoj M-L: Use of Health Services, Mental IIIness, and Self-Rated Disability and Health in Medical Inpatients. Psychosomatic Med 2002, 64:668-675.

II. Bures R: Childhood Residential Stability and Health at Midlife. Am J Public Health 2003, 93: I I 44- I I 48.

12. Wells K: Quality of Care for Primary Care Patients With Depression in Managed Care. Arch Fam Med 1999, 8:529-536.

13. Thompson D, Hylan T, McMullen W, Romeis M, Buesching D, Oster G: Predictors of a Medical-Offset Among Patients Receiving Antidepressant Therapy. Am J Psychiatry 1998, I 55:824-827.

14. Sturm R: The Myth of Medical Cost Offset. Am J Psychiatry 200I, 52:738-740.

15. Scott J, Thorne A, Horn P: Effect of a multifaceted approach to detecting and managing depression in primary care. $B M J$ 2002, 325:95I-4.

16. Rickert VI, Pope SK, Tilford JM, Scholle SH, Kelleher KJ: The Effects of Mental Health Factors on Ambulatory Care Visits by Rural Teens. Journal of Rural Health 1996, I2:160-88.

17. Rohrer JE, Culica DV: Identifying High-Users of Medical Care in a Farming-Dependent County. Health Care Manage Rev 1999 , 24(4):28-34.

18. Rohrer JE, Vaughn T, Knott A, Westermann J: Health status and health professional visits in a rural area. Health Services Management Research 2000, I3: I 27-132.

19. Manning WG, Wells KB: The effects of psychological distress and psychological well-being on use of medical services. Medical Care 1992, 30(6):54|-553.

\section{Pre-publication history}

The pre-publication history for this paper can be accessed here:

http://www.biomedcentral.com/1471-2458/4/3/prepub
Publish with Biomed Central and every scientist can read your work free of charge

"BioMed Central will be the most significant development for disseminating the results of biomedical research in our lifetime. "

Sir Paul Nurse, Cancer Research UK

Your research papers will be:

- available free of charge to the entire biomedical community

- peer reviewed and published immediately upon acceptance

- cited in PubMed and archived on PubMed Central

- yours - you keep the copyright
BiolMedcentral 